\title{
Sufficiency, liberal societies and environmental policy in the face of planetary boundaries
}

\author{
Muller, Adrian ; Huppenbauer, Markus
}

\begin{abstract}
Sufficiency is not a goal of environmental policy-making as is efficiency. In view of the planetary boundaries, this paper instead proposes that sufficiency should amend the notion of liberal society. The classic vision of liberal societies has been based on the core values of individual freedom, the no-harm principle and social justice together with the related virtues of courage, prudence and justice. By adding sufficiency, we introduce a fourth core value, one which is necessary for dealing with planetary boundaries. Temperance, the virtue linked to sufficiency, becomes an important part of this.
\end{abstract}

DOI: https://doi.org/10.14512/gaia.25.2.10

Posted at the Zurich Open Repository and Archive, University of Zurich

ZORA URL: https://doi.org/10.5167/uzh-125412

Journal Article

Published Version

Originally published at:

Muller, Adrian; Huppenbauer, Markus (2016). Sufficiency, liberal societies and environmental policy in the face of planetary boundaries. GAIA, 25(2):105-109.

DOI: https://doi.org/10.14512/gaia.25.2.10 


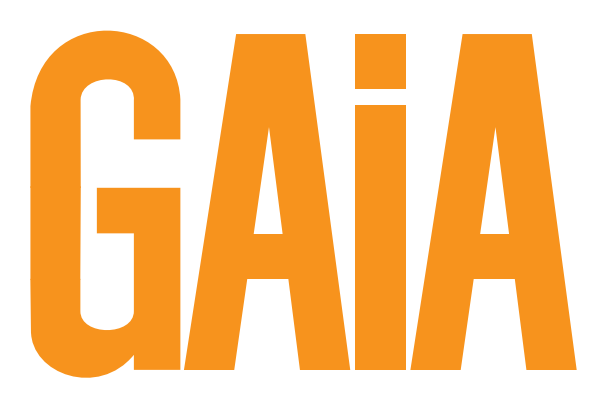

$2 \mid 2016 \begin{aligned} & \text { ECOLOGICAL PERSPECTIVES FOR SCIENCE AND SOCIETY } \\ & \text { ÖKOLOGISCHE PERSPEKTIVEN FÜR WISSENSCHAFT UND GESELLSCHAFT }\end{aligned}$

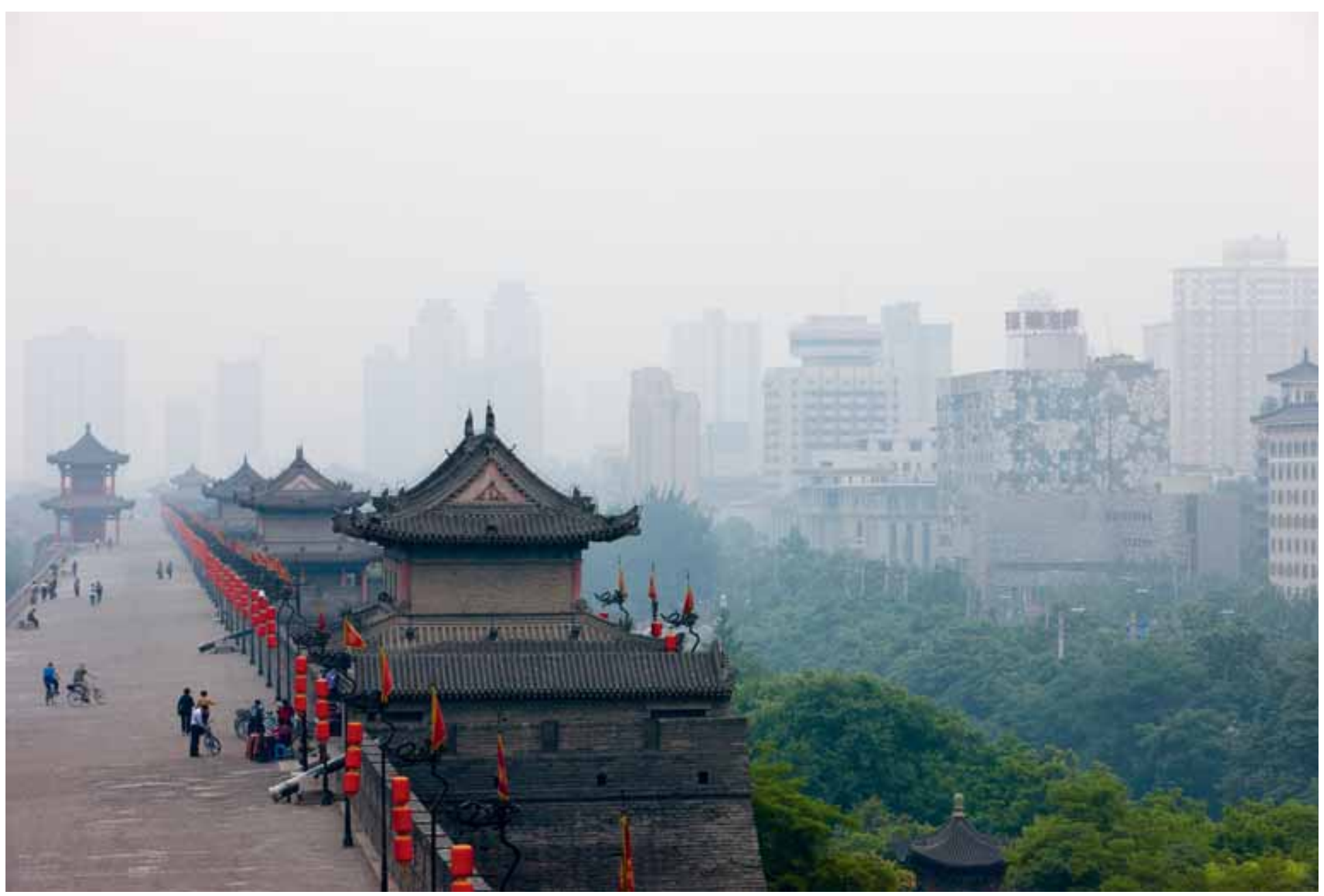

FORSCHUNG FÜR UND ÜBER TRANSFORMATION

- FRACKING UND LANDSCHAFT

- NACHHALTIGKEIT ALS FORM DES NIESSBRAUCHS 


\title{
Sufficiency, Liberal Societies and Environmental Policy in the Face of Planetary Boundaries
}

\author{
The classic vision of liberal societies has been based on the \\ core values of individual freedom, the no-harm principle and \\ social justice together with the related virtues of courage, prudence \\ and justice. By adding sufficiency, we introduce a fourth core value, \\ one which is necessary for dealing with planetary boundaries. Temperance, \\ the virtue linked to sufficiency, becomes an important part of this.
}

Sufficiency is not a goal of environmental policy-making as is efficiency. In view of the planetary boundaries, this paper instead proposes that sufficiency should amend the notion of liberal society.

Adrian Muller, Markus Huppenbauer

\begin{abstract}
Sufficiency, Liberal Societies and Environmental Policy in the Face of Planetary Boundaries | GAIA 25/2 (2016): 105-109 | Keywords:
\end{abstract} efficiency, environmental policy, individual freedom, justice, liberal society, no-harm principle, planetary boundaries, policy instruments, sufficiency, virtues

G reenhouse gas concentrations are rising, and meeting the two-degree target becomes increasingly improbable (IPCC 2014). But not only climate change challenges humanity. At least four out of ten environmental planetary boundaries have been transgressed or will likely be so soon, and many regional and local environmental problems persist with substantial impact on the life of individuals (Steffen et al. 2015). Technical and economic efficiency and innovation are promoted to address those challenges, internalizing the societal costs of production and consumption and increasing resource use efficiency. Policy instruments such as emission standards or environmental taxes support these efforts.

However, increased efficiency and innovation may not suffice to keep societies' environmental impacts within identified boundaries. "Sufficiency" is thus increasingly being promoted as a complementary approach when it comes to dealing with these challenges of sustainability (Alcott 2008, Mont and Plepys 2008, IPCC 2014, Allcott and Mullainathan 2010)..$^{1}$ In general terms, sufficiency aims at reducing consumption levels of individuals, linked to an attitude of temperance and to particular conceptions of a "good life" emphasizing non-material aspects and consciousness for the environment.

However, there are many different conceptions of sufficiency. Often, they are not clearly defined, and suggestions for putting them into action run into difficulties. In particular, suggestions for making sufficiency a topic for climate change mitigation and a subject of general environmental policy discussions face opposition from liberal people, as such suggestions are often consid-

1 See also www.unep.org/resourceefficiency/Consumption/

EducationLifestylesandYouth/Sustainable Lifestyles/tabid/101304/Default.aspx. ered as bearing a threat to individual freedom. Our goal here is to clarify why difficulties arise with the current conceptions of sufficiency. We then suggest how sufficiency should be framed in societies built on liberal core values, such as modern Western societies, and how our conception helps to avoid the identified difficulties.

\section{Sufficiency: The Current Discussion}

The discussion of environmental problems in modern Western societies strongly relates to what we regard as the three core values of liberal societies: "individual freedom", the "no-harm principle" and "social justice". There is a wide range of notions of a liberal society. To name just a few, there is a more "libertarian" notion as promoted by Nozick (1974), where individual freedom is most important, a more "social" one, where rather equality is key (Rawls 1971), or a "constitutional" one (Locke 2016), where the relation between citizens and the state with respect to the defense

Contact: Dr. Adrian Muller | Federal Institutes of Technology ETH Zurich | Chair of Environmental Policy and Economics PEPE | Zurich | Switzerland and Research Institute of Organic Agriculture FiBL | Department of Socioeconomics | Ackerstr. 113 | 5070 Frick | Switzerland | Tel.: +41628657252 | E-Mail: adrian.mueller@fibl.org

Prof. Dr. Markus Huppenbauer | University of Zurich | Center for Religion, Economy and Politics (CREP) | Zurich | Switzerland | E-Mail: huppenbauer@ethik.uzh.ch

(C) 2016 A. Muller, M. Huppenbauer; licensee oekom verlag. This is an Open Access article
distributed under the terms of the Creative Commons Attribution License
(http://creativecommons.org/licenses/by/3.0), which permits unrestricted use, distribution,
and reproduction in any medium, provided the original work is properly cited. 
of their life, liberty and property is central. For our discussion, we do not adopt one specific notion; we refer to all societies that are organized around the three core values named above, be some of them more or less central in its concrete implementation, but where all of them play a crucial role. Our considerations thus apply to a variety of such notions of liberal societies that have been suggested.

Within such notions of liberal societies, governmental restrictions of individual freedom are regarded as acceptable if the freedom of others or justice are at stake, for instance, in the case of damage to the livelihoods of others as a result of some citizens' actions (e.g., by polluting water). In contrast, sufficiency targets actions of individuals in relation to certain attitudes and values that they should adopt without direct reference to actual individual damage or issues of social justice. It aims at influencing individuals' lifestyle and beliefs on what a "good life" is towards "environmentally friendly” behavior and towards supporting sustain- sponsible" citizens, voluntarily changing behavioral patterns towards temperance and reduced environmental impacts.

Thus, sufficiency could complement the classical approaches to deal with environmental problems, but no existing conception of sufficiency seems to provide guidance on how to implement it while being compatible with the core values of liberal societies.

\section{A New Approach to Sufficiency and Liberal Societies}

We resolve this incompatibility by framing sufficiency as an amendment to the core values determining liberal societies rather than by framing it as a concept to guide environmental policy and behavior within established notions of liberal societies.

We take as our starting point an illustrative narrative on the basis of liberal societies: historically, natural boundaries to societies

\section{Sufficiency is not about how to implement a specific consumption level with each individual, but how much of a specific individual consumption level is possible in relation to the consumption of all other citizens and the corresponding aggregate.}

ability as a societal goal. Exercising influence on personal lifestyles and beliefs is difficult in liberal societies, because values, lifestyle and conceptions of "good life" are core aspects of individual freedom and are conceived as private.

Different conceptions of sufficiency have been proposed. We differentiate between three of them, without attempting an indepth review. First, sufficiency is often framed in accordance with accepted incentive schemes in liberal societies, for example, economic incentives. It basically reproduces economic efficiency, albeit often in a long-term and encompassing manner (e.g., Princen 2005, Linz 2012). Sufficiency as an approach for addressing the challenges mentioned above is then no longer additional to efficiency. Second, some authors frame sufficiency as a policy goal on par with other well-established policy goals such as increased energy efficiency. As a policy goal, it would have to be complemented with policy instruments to set incentives for adopting the corresponding "sufficient" lifestyles, just as policy instruments exist to support increased energy efficiency. When implemented as direct governmental regulation of individual lifestyles, such instruments lead to conflicts with individual freedom as a core value of liberal societies (Schramme 2011). Consequently, it has been suggested to weaken this core value, which however can lead to paternalism or even eco-dictatorship (Wurster 2013). Third, sufficiency is sometimes framed as a guiding principle for individual action in face of environmental problems (e.g., Stengel 2011). Its operationalization would be also difficult in liberal societies. It again either resorts to efficiency measures or to illiberal paternalism, or it relies on the mere hope that people become "more re- were basically given by lack of knowledge and power. They often hindered the societies' development. Transgressing the boundaries was essential to secure new livelihoods and to assure survival; the presence of courageous and free individuals was important to meet the challenge. A livable human society, to continue this narrative, emerged by complementing individual freedom with both the no-harm principle to curb individual actions that interfered with the freedom of others, and with social justice to moderate inequalities.

Since then, the role of boundaries has changed fundamentally. Today, limits to societies are rather derived from planetary boundaries for key environmental indicators that have to be respected to assure safe living conditions for societies and the individuals living in them (Steffen et al. 2015). These new boundaries seem to exist independently of knowledge or power deficits of societies. They rather seem to originate from the unprecedented power of societies to alter and negatively affect the environment. With these new boundaries, survival is tightly linked to respecting rather than transgressing them.

Respecting planetary boundaries proves to be challenging. To address the challenge, we suggest that sufficiency should be framed as an additional aspect determining what a liberal society may mean today, accounting for the boundaries that have to be respected for allowing safe living conditions for human societies. Respecting these boundaries and not impeding with safe living conditions on a planetary scale thus becomes a forth core value in an amended notion of liberal societies. We therefore suggest framing sufficiency as this fourth core value. By doing so, our discus- 
sion on sufficiency develops the discussion on planetary boundaries as an urgently needed new paradigm to "(integrate) the continued development of human societies and the maintenance of the earth system in a resilient and accommodating state" (Steffen et al. 2015, p. 736).

However, sufficiency relates to both societal goals and individual behavior. Hence, we propose combining the narrative of liberal societies presented above with the well-known philosophical concept of (cardinal) virtues to illustrate how sufficiency as framed above may relate to individuals in liberal societies. In the past, where boundaries had to be transgressed for survival and flourishing, three of the four cardinal virtues were decisive, namely courage, prudence and justice. They relate to the core values of the notions of liberal societies mentioned above: The virtue of courage relates to the core value of individual freedom, prudence relates to the noharm principle and justice relates to social justice. The fourth cardinal virtue "temperance" plays no role in this liberal narrative. But temperance becomes decisive in the amended notion of liberal society proposed here, where absolute levels of actions and impacts and respecting rather than transgressing boundaries form a fourth core value "sufficiency". Temperance is the virtue that corresponds to sufficiency. Temperance can also be seen as a typical virtue of sustainability (Sandler 2007). The concept of virtues thus helps to illustrate which type of individual action may relate to sufficiency as a fourth core value of liberal societies.

Sufficiency is usually formulated and exemplified as a reduction of actions and consumption of goods and services with high environmental impacts, but in fact it doesn't matter whether one single person drives a heavy fossil-fuel based car or eats a lot of meat (figure 1). Citizens in liberal societies may have such or other consumption patterns, and it is not necessary that everybody reduces all of his or her specific consumption. However, it is necessary that the current average total consumption level of goods and services with high environmental impacts drops to much lower levels in order to sustain appropriate living conditions for individuals in the future. Therefore, sufficiency is not about how the state may implement a specific consumption level of such goods and services with each individual. Rather, it is about how much of a specific individual consumption level is possible in relation to the consumption of all other citizens and the corresponding aggregate. Implementing sufficiency thus faces a threefold challenge: it has to take into account the heterogeneity of human beings and their needs and aims, as well as considerations of justice, while the whole society and its citizens develop in a certain direction of ag-

FIGURE 1: Sufficiency is a controversial topic in liberal societies. Usually, people link the concept of sufficiency with eating less meat or flying less, but that is far too simple as is demonstrated in this article.

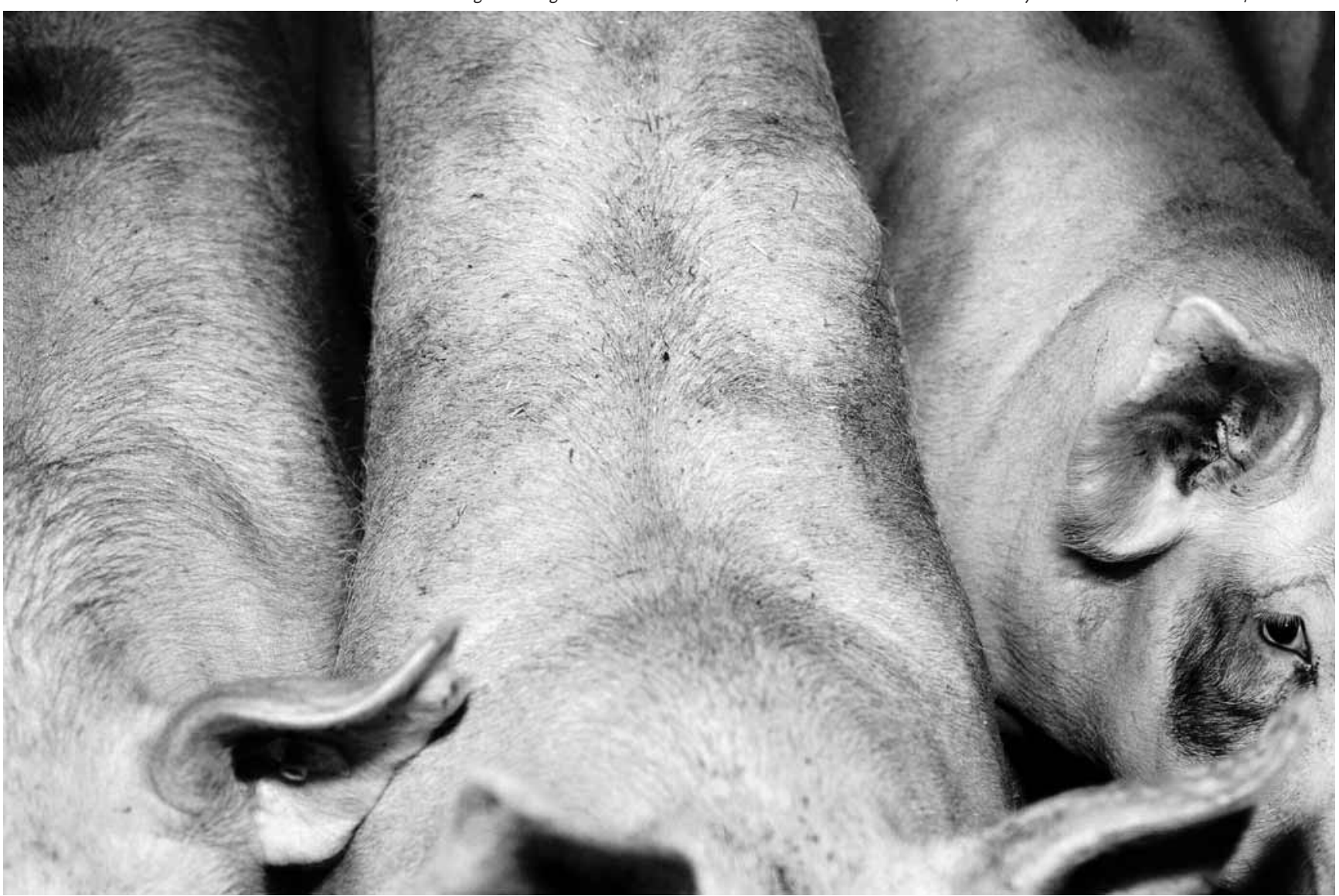


gregate impact levels that are compatible with planetary boundaries. Sufficiency is compatible with different individuals showing high consumption levels in different goods (one may often use the car, another may consume a lot of meat), but it is not compatible with all individuals having high consumption levels for many goods. Due to justice, it is neither compatible with few individuals consuming most goods while the others have to follow overall low consumption levels.

\section{Sufficiency and Policy Making}

Framing sufficiency via the amended notion of liberal societies within the planetary boundaries explicitly makes the argument that sufficiency is much more than another approach to environmental policy making. Increasing sufficiency cannot be achieved by policy instruments in the spirit of payments for increased energy efficiency or an environmental tax, for example. Our conception of sufficiency aims at rethinking the notion of the liberal society as a frame for societal organization and policy making. It addresses the frame for policy making rather than the policy making itself.

\section{Temperance, lived in moderation, allows for excesses that are so needed in human societies.}

Sufficiency thus addresses core aspects of liberal societies and how citizens live together. Some of the difficulties with the existing conceptions of sufficiency arise because the need to address these core aspects is not made explicit. In particular, our new approach avoids the inconsistency of sufficiency with liberal core values. It does not aim at implementing sufficiency within the frame of classical liberal societies; it aims at implementation via redefining the frame that determines how liberal societies should be conceived. The conflicts between the three core values of classical liberal societies and sufficiency are then no longer inconsistencies between different political concepts. Rather, following the amended notion of liberal societies suggested here, they emerge as tradeoffs between four core values. That is, the conflicts are on the same level and of the same quality as the trade-offs between individual freedom and the no-harm principle or social justice, which already exist between the core values of classical liberal societies. Tradeoffs between values can be addressed within the established culture of social discourse and policy making in liberal societies. Dealing with such trade-offs (between core values) has a long tradition in liberal societies.

Adding a fourth value to the three established ones "individual freedom", "no-harm principle" and "social justice" requires rethinking the relations between all values and the consequences for policy making. The process of policy instrument design can only start once this has been clarified. The time-line for establishing sufficiency as fourth core value involves a few generations rather than a few years and it requires a deepened political and societal discourse and adapted educational systems (Dobson 2003).

The new idea of conceiving sufficiency as a core value explicitly aims at developing a new type of liberal society. Sufficiency is understood as the currently missing additional core value guiding liberal societies to respect planetary boundaries and have a good prospect to survive within those. We emphasize again that sufficiency is thus explicitly not understood as a way of framing policy goals and policy making within established notions of liberal societies, similar to goals and policies related to efficiency, for example. Admittedly, developing ideas for new societies is an old issue, and such efforts in an environmental context in the $1960 \mathrm{~s}$ largely failed. But this is no reason against discussing fundamental societal changes and visions again, to explore the potential of sufficiency.

\section{Taking Action for Sufficiency}

Behind the existing support measures for the implementation of the classical liberal core values and for dealing with resulting trade-offs, there is a long political and societal process. A similar process would have to begin now for the new core value represented by sufficiency. There is need for a discussion on how liberal policy making is influenced by this additional core value, which is linked to the virtue of temperance, and by acknowledging the existence of environmental planetary boundaries and their relevance for societies' living conditions.

A good starting point would be to broaden and deepen the societal discourse. Society and citizens can contribute to this via making sufficiency a topic in governmental discourse, the media, arts, research, youth culture and in the educational system. Establishing such a process could draw inspiration from analyzing other recent large-scale societal transitions, for example, regarding gender equality and role models, sexuality and life forms, the role of religion, or the role of authority versus respect in child care and education. The state may importantly contribute to the process in some aspects, in others less so. State action foremost consists in establishing structures, opportunities and contexts within which this discourse can be led, without knowing concretely which guidance may lead citizens towards increased sufficiency, as identifying this guidance is indeed the goal of this discourse.

We close with some general thoughts on important aspects for implementing sufficiency.

First, one needs to think about the institutions that come with the additional core value. Existing institutions can serve as a good reference point: how were they established to implement important aspects of the classical core values of liberal societies and to address emerging trade-offs. As examples could serve: property rights for supporting individual freedom and wealth redistribution for supporting social justice. Developing institutions for implement- 
ing the core value "justice" took generations in modern Western societies and is still an ongoing process (cf., e. g., the debates on "fair" wages or tax competition). Drawing this parallel emphasizes that increasing sufficiency is a lengthy process and a long-term issue.

Second, according to the notion of the classical liberal society, governmental action restricting individual freedom is legitimate when dealing with situations where the no-harm principle is directly violated or when promoting social justice. In our amended notion, such governmental action is also legitimate when the planetary boundaries are in danger of being transgressed. Accordingly, there is no need to argue for legitimation of governmental action via direct individual damage to others or justice. Such legitimation is usually prohibitively difficult, if not impossible, as individual contributions to transgressing environmental planetary boundaries are negligible, and the cause-effect chains between single individuals can never be reproduced (Lichtenberg 2010). We emphasize that we do not address the shape such governmental action might take. The aim here is to contribute to the discussion of sufficiency by providing a new basis for the understanding of sufficiency that may help to overcome the difficulties this discussion faces today. Concrete aspects of implementation need then to be identified in the societal discourse we try to give new momentum to.

Third, sufficiency as proposed here generally does not relate to individuals' everyday intuitions. We suggest that this also contributes to particular challenges when implementing sufficiency, just as absence of intuition may challenge solving complex problems in complex environments (Bennet and Bennet 2008). Individuals have a good intuition for individual freedom and what its restriction may mean. Intuition is less developed for social justice which is more difficult to grasp as it does not only relate to single individuals, but to questions of distribution of assets between individuals. It thus necessitates a perspective that goes beyond the single individual. Nevertheless, in the process of establishing the needed institutions for effectively living and enacting justice, a certain level of intuition for social justice clearly has been developed in liberal societies. Planetary boundaries, however, are entirely nonintuitive to individuals. Individuals do not have an intuitive understanding of what it means to live in a world which respects planetary boundaries. Developing such understanding is only starting now. Discussing sufficiency as an amended notion of a liberal society is also a learning ground to develop the needed intuition and institutions for societies to live and act in accordance with these planetary boundaries.

Finally, we emphasize that temperance is an utterly liberal virtue. Calling for temperance avoids fanaticism and paternalism as virtues have to be implemented self-reflexively. This self-reflexivity does not change the nature of courage, justice and prudence when lived in courageous, just and prudent ways; it reinforces them. But it makes temperance human. Temperance, lived in moderation, allows for excesses that are so needed in human societies.
We thank Ivo Wallimann, Ortwin Renn and two anonymous reviewers for very helpful comments on this text; AM would like to thank the Mercator Foundation Switzerland for funding part of this work in the context of the University Research Priority Program for Ethics at the University of Zurich.

\section{References}

Alcott, B. 2008. The sufficiency strategy: Would rich-world frugality lower environmental impact? Ecological Economics 64/4: 770-786.

Allcott, H., S. Mullainathan. 2010. Behavior and energy policy. Science 327/5970: 1204-1205.

Bennet, A., D. Bennet. 2008. The decision-making process for complex situations in a complex environment. In: Handbook on decision support systems. Vol. 1: Basic themes. Edited by F. Burstein, C. W. Holsapple. Berlin: Springer.

Dobson, A. 2003. Citizenship and the environment. Oxford, UK: Oxford University Press.

IPCC (Intergovernmental Panel on Climate Change). 2014. Climate change 2014: Mitigation of climate change. Contribution of Working Group III to the Fifth Assessment Report of the Intergovernmental Panel on Climate Change. New York: Cambridge University Press.

Lichtenberg, J. 2010. Negative duties, positive duties, and the "new harms". Ethics 120/3: 557-578.

Linz, M. 2012. Weder Mangel noch Übermaß. Warum Suffizienz unentbehrlich ist. Munich: oekom.

Locke, J. 2016 (orig. 1689). Second treatise of government and a letter concerning toleration. Edited by M. Goldie. Oxford, UK: Oxford University Press.

Mont, O., A. Plepys. 2008. Sustainable consumption progress: Should we be proud or alarmed? Journal of Cleaner Production 16/4: 531-537.

Nozick, R. 1974. Anarchy, state, and utopia. Oxford, UK: Basil Blackwell.

Princen, T. 2005. The logic of sufficiency. Cambridge, MA: MIT Press.

Rawls, J. 1971. A theory of justice. Cambridge, MA: Belknap.

Sandler, R. L. 2007. Character and environment. A virtue-oriented approach to environmental ethics. New York: Columbia University Press.

Schramme, T. 2011. When consumers make environmentally unfriendly choices. Environmental Politics 20/3: 340-355.

Steffen, W. et al. 2015. Planetary boundaries: Guiding human development on a changing planet. Science 347/6223. doi:10.1126/science.1259855.

Stengel, O. 2011. Suffizienz. Munich: oekom.

Wurster, S. 2013. Comparing ecological sustainability in autocracies and democracies. Contemporary Politics 19/1: 76-93.

Submitted July 7, 2015; revised version accepted May 12, 2016.

\section{Adrian Muller}

Born 1971 in Zurich, Switzerland. 1991 to 1996 studies in theoretical physics at the University of Zurich. $2000 \mathrm{PhD}$ in theoretical physics. 2000 to 2009 research positions in

Zurich and Gothenburg. Since 2009 senior researcher at the Research Institute of Organic Agriculture FiBL and the Federal Institutes of Technology ETH Zurich. Research interests: sustainable food systems and environmental policy design.

\section{Markus Huppenbauer}

Born 1958 in Klosters, Switzerland. 1990 doctorate in philosophy at the University of Zurich. 1992 to 2016 positions at the Protestant Reformed Church of Zurich, the Swiss Study Foundation, and the University Research Priority Program for Ethics at the University of Zurich.

Since June 2016 director of the Center for Religion, Economy and Politics (CREP) at the University of Zurich. 2006 adjunct professor for ethics. Research interests: environmental ethics and business ethics. 